P.I. Reynolds MD, W.B. Fang MD, A.F.L. VanDerSpek MD

\title{
The onset of ablation of the evoked adductor pollicis muscle twitch in children: a clinical perspective
}

The time to loss of the adductor pollicis muscle response to ulnar nerve stimulation at I $\mathrm{Hz}$ (twitch) after succinylcholine, $1.5 \mathrm{mg} \cdot \mathrm{kg}^{-1}$ intravenously (IV), or vecuronium, $0.1 \mathrm{mg} \cdot \mathrm{kg}^{-1}$ (IV), administration was assessed visually in 134 children, age $2-13$ yr, during clinicully determined, deep halothane, enflurane and isoflurane anaesthesia. The overall time to twitch ablation and duration of succinylcholine's action is in agreement with published times obtained under controlled experimental conditions; the onset time following vecuronium is comparable to thase observed during a similar anaesthetic background measured under controlled experimental conditions. Twitch ablation after succinylcholine was achieved in half the time needed following vecuronium regardless of anaesthetic agent. Succinylcholine's and vecurontum's onset time as well as succinylcholine's duration is adequately assessed by the out. lined, simple clinical means. The choice of inhalation agent does not affect the time to visible twitch ablation in a clinically relevant manter; nor does it make an appreciable difference, in clinical terms, in succinylcholine's duration of action.

\section{Key words}

NEUROMUSCULAR RELAXANTS: succinylcholine, vecuronium; ANAESTHETICS, INHALATION: isoflurane, enflurane, halothane; NEUROMUSCULAR BLOCKADE: measurement.

From the University of Michigan Medical Center, The Department of Anesthesiology, C.S. Mott Children's Hospital, Room C4139, Box 0800, Ann Arbor, MI 48109-0800.
General anaesthesia is commonly induced in children by inhalation of an anaesthetic vapour in an oxygen/nitrous oxide mixture. Following induction of anaesthesia, an intravenous infusion is started and a muscle relaxant is administered to facilitate intubation and surgery. Previous work suggests that inhalation agents may affect the onset, potency, and duration of action of muscle relaxants. These conclusions have been based on studies which relied on controlled experimental conditions while measurements were made with special equipment. Clinical practice usually differs from those studies in that clinical conditions rarely match those under which these drug effects were established. Laboratory grade equipment (mass or infrared spectrometry for end-tidal agent detection, precision nerve stimulators, isometric force cransducers with specialized armboards and recording equipment) is seldomly available or used in clinical practice. Anaesthetic depth becomes a matter of clinical judgement and simple, inexpensive equipment is used to assess neuromuscular transmission. No study to date has compared the results obtained under clinical conditions in children with those from controlled experiments. Thus, the clinician may wonder if, and how, his practice deviates from experimental observations. Therefore, we studied the onset time of twitch depression following administration of commonly used doses of succinylcholine and vecuronium during halothane, enflurane, and isoflurane anaesthesia in children. The duration of succinylcholine induced twitch depression was also studied. Clinical conditions were utilized while measurements were made with simple clinical tools. The results were compared with the times determined under controlled experimental conditions reported in the literature.

\section{Methods}

This study was approved by the Committee on Human Use of the University of Michigan. Subjects selected for this study were 2-13 years of age and of ASA physical status I or II. They were free of known neuromuscular, cardiovascular, or renal disease and were scheduled to 
undergo elective surgical procedures which required general anaesthesia and tracheal intubation. Anaesthesia was provided by a randomly assigned anaesthesia team, which consisted of trainees in anaesthesiology (residents and student nurse anaesthetists) under the supervision of staff anaesthetists and certified nurse anaesthetists. No premedication was given; volatile anaesthetics and muscle relaxants were randomly assigned. Anaesthesia was induced with inhalation of a $70 / 30 \mathrm{~N}_{2} \mathrm{O} / \mathrm{O}_{2}$ mixture with stepwise-increased concentrations of halothane, enflurane, or isoflurane while monitors were applied, including precordial stethoscope, pulse oximeter, blood pressure cuff, electrocardiogram, nerve stimulator, and tempera ture probe. A nonrebreathing system was used for the inhalation induction. End-tidal levels of anaesthetic agents were not measured. An intravenous catheter was inserted and the ulnar ncrve was stimulated transcutaneously via two surface electrodes placed 2 and $9 \mathrm{~cm}$ proximal to the ulnar head (at the wrist) with supramaximal, square wave stimuli of $0.2 \mathrm{msec}$ duration, at a frequency of $1 \mathrm{~Hz}$ (Bard Biomedical, Peripheral Nerve Stimulator, model 750 Digital). The evoked thenar muscle response (twitch) was noted visually by an observer who was blinded to both anaesthetic and muscle relaxant. When a level of anaesthesia was obtained sufficiently deep for the patient to be intubated, as determined by the anaesthesia team, either succinylcholine $\left(1.5 \mathrm{mg} \cdot \mathrm{kg}^{-1}\right)$ or vecuronium $\left(0.1 \mathrm{mg} \cdot \mathrm{kg}^{-1}\right)$ was

TABLE 1 Mean ( $=$ SD) age, height and weight of patients in the three anaesthetic groups

\begin{tabular}{llll}
\hline $\begin{array}{l}\text { Andesthetic } \\
\text { Enfluranc } \\
(\mathrm{n}=44) \\
\begin{array}{l}\text { Isoflurane } \\
\text { (n=4d) }\end{array}\end{array}$ & $\begin{array}{l}\text { Age } \\
\text { (years) }\end{array}$ & $\begin{array}{l}\text { Height } \\
(\mathrm{cm})\end{array}$ & $\begin{array}{l}\text { Weight } \\
(\mathrm{kg})\end{array}$ \\
$\begin{array}{l}\text { Halothane } \\
\text { (n=46) }\end{array}$ & $5.8 \pm 3.5 \pm 3.3$ & $120.1 \pm 22.5$ & $24.7 \pm 12.4$ \\
ANOVA & $\mathrm{F}=0.921$ & $\mathrm{~F}=1.106$ & $\mathrm{~F}=1.472$ \\
\hline
\end{tabular}

No significant differences were present between groups. given at the hub of an intravenous (IV) catheter in a running IV infusion. Timing started at the end of the relaxant injection. The time at which the visible twitch was lost completely was recorded $\left(\mathrm{T}_{1}\right)$ in all patients. In patients who received succinylcholine, the time at which the first visible twitch returned was also determined $\left(\mathrm{T}_{2}\right)$. Spontaneous recovery from relaxation induced by vecuronium could usually not be observed because muscle relaxation outlasted the surgical procedure in most patients, necessitating the use of reversal agents. The $T_{1}$ to $T_{2}$ interval was defined as the duration of twitch ablation. Analysis of variance (ANOVA) was used to compare the groups receiving the relaxants and anaesthetic agents in terms of age, height, weight, $T_{1}, T_{2}$ and $T_{1}-T_{2}$ interval.

\section{Results}

The three groups of subjects (n $=134$ ) receiving the inhalational anaesthetics did not differ significantly with respect to age, weight, and height (Table I). The patients who were given intravenous succinylcholine did not differ from those receiving vecuronium with respect to age, weight, and height. Inhalation induction with halothane took typically 4-8 min before an adequately deep level of anaesthesia was obtained, whereas an enflurane or iso. flurane induction took 7-14 min. The final inspired concentration of anaesthetic vapour was three to five per cent; the final level varied from patient to patient. The mean time to loss of twitch in patients receiving succinylcholine was not significantly different among the three anacsthetic groups nor did the mean time to loss of twitch differ significantly among these groups after vecuronium administration (Table II). The mean time to loss of twitch after succinylcholine administration was significantly shorter (approximately one half) than that after vecuronium administration in each anaesthetic group (Table II). The overall mean time to loss of twitch in the succinylcholine patients of all three anaesthetic groups combined was $40.6 \pm 18 \mathrm{~s}$ (mean \pm SD) while it was $89.7 \pm 25 \mathrm{~s}$ (mean $\pm \mathrm{SD}$ ) in the patients receiving vecuronium; this difference was significant ( $F=169.5, p<0.0001$, ANOVA). The mean duration of twitch ablation after succinylcholine administration did not differ significantly among the

TABLE II The mean ( \pm SD) time to loss of thenar muscle twitch in seconds after succinylcholine or vecuronium administration in three anaesthetic groups

\begin{tabular}{lllll}
\hline Relaxam & Enflurane & Halothane & Isofurane & ANOVA \\
\hline Succinylcholine & $35.9 \pm 16.0$ & $46.4 \pm 19.1$ & $39.9 \pm 18.4$ & $\mathrm{~F}=1.93$ \\
$1.5 \mathrm{mg} \cdot \mathrm{kg}^{-1}$ & $\mathrm{n}=23$ & $\mathrm{n}=21$ & $\mathrm{n}=23$ & $\mathrm{p}<0.1532$ \\
Vecuronium & $92.9 \pm 25.9$ & $92.4 \pm 25.4$ & $83.5 \pm 23.0$ & $\mathrm{~F}=0.97$ \\
$0.1 \mathrm{mg} \cdot \mathrm{kg}^{-1}$ & $\mathrm{n}=21$ & $\mathrm{n}=23$ & $\mathrm{n}=21$ & $\mathrm{p}<0.3835$ \\
ANOVA & $\mathrm{F}=78.2$ & $\mathrm{~F}=45.5$ & $\mathrm{~F}=48.6$ & \\
& $\mathrm{p}<0.0001$ & $\mathrm{p}<0.0001$ & $\mathrm{p}<0.0001$ & \\
\hline
\end{tabular}


TABLE III Duration of twitch ablation after succinylcholine administration in the anaesthelic groups (mean \pm SD)

\begin{tabular}{lll}
\hline Anoestietic & $\begin{array}{l}\text { Duration } \\
\text { (seconds) }\end{array}$ & $n$ \\
\hline Enflurane & $225.9 \pm 47.8$ & 22 \\
Halothane & $252.8 \pm 73.5$ & 21 \\
Isofluranc & $249.3 \pm 119.1$ & 23 \\
\hline
\end{tabular}

The duration of iwitch depression was not significantly differcint between the anaesthetic groups $(F=0.63, p<5.536$. ANOVA $)$.

groups of inhalation agents (Table III). The overall mean duration of twitch ablation in all patients receiving succinylcholine, regardless of the anaesthetic group, was $242 \pm 85$ s (mean \pm SD).

\section{Discussion}

In children, it is common practice to induce general anaesthesia with a volatile anaesthetic followed by the intravenous administration of a relatively large dose (larger than the $\mathrm{ED}_{95}$ ) of a muscle relaxant for prompt, full relaxation prior to intubation. Onset of relaxation is judged, in clinical practice, by signs such as the cessation of spontaneous muscle movements and respiration as well as cessation of fasciculations in the case of succinylcholine. Neuromuscular transmission is also assessed using simple, inexpensive nerve stimulators which elicit a visible muscle twitch. When the twitch is lost, blockage of neuromuscular transmission has oceurred and limb muscle relaxation is inferred. Studies evaluating onset, magnitude and duration of relaxation carefully quantify twitch responses from recorded tracings of, for example, the force developed by the adductor pollicis muscle upon supramaximal ulnar nerve stimulation - for the purposes of this discussion referred to as the "adductor pollicis technique." Prevailing anaesthetic conditions (e.g., endtidal levels of the inhalation agents) are controlled and standardized. Such controlled studies suggest that the loss of the visible twilch of the thenar muscles upon supramaximal stimulation of the ulnar nerve is consistent with the loss of 95 to 98 per cent of the mechanical force developed by the adductor pollicis muscle.' The loss of visible twitch is uscd commonly as an indication of adequate muscle relaxation for tracheal intubation; it has not before been evaluated and compared to results of more controlled studies in paediatric patients.

The overall mean time to twitch ablation of the thenar muscles $(40.6 \pm 18 \mathrm{~s})$ following succinylcholine administration in this study is in agreement with previous studies. Cunliffe et al. recorded a time to 95 per cent twitch depression of $40.8 \pm 3 \mathrm{~s}$ after succinylcholine, 1.5 $\mathrm{mg} \cdot \mathrm{kg}^{-1} \mathrm{IV}$, during a thiopental-narcotic, nitrous oxide- oxygen technique in children; neuromuscular transmission was monitored with the adductor pollicis technique using stimuli of $0.2 \mathrm{~ms}$ duration delivered via needle electrodes at a rate of $0.15 \mathrm{~Hz}^{2}$ Blackbum and Morgan observed a mean time to 95 per cent twitch depression of $49 \pm 2 \mathrm{~s}$ (adductor pollicis technique; rate $0.5 \mathrm{~Hz}$, duration $0.1 \mathrm{~ms}$ ) after succinylcholine, $1 \mathrm{mg} \cdot \mathrm{kg}^{-1} \mathrm{IV}$, during a methohcxital-fentanyl-nitrous oxide-oxygen anaesthetic in adults. ${ }^{3}$ The current study differs in important aspects from the other two. Twitch was monitored visually, while stimulation was accomplished at a higher rate of stimulation $(1 \mathrm{~Hz})$ with a simple stimulator. Furthernore, volatile anuesthetics were used, while anaesthetic levels were determined by clinical judgement, probably resulting in variations of anaesthetic depth. In spite of these differences, the onset times in this study are in a remarkable agreement with the onset time of succinylcholine from controlled experiments. It appears that under the conditions of this study, volatile anaesthetics have little effect on succinylcholine's onset time compared to its onset time during a barbiturate-narcotic technique, when used in similar doses.

The overall mean duration (242 $\pm 85 \mathrm{~s}$ ) of twitch ablation (end of injection until first visible twitch) after succinylcholine in the present study is consistent with the duration (204 $\pm 54 \mathrm{~s}$; start of twitch decrement to ten per cent recovery) of succinylcholine-induced relaxation during halothane anaesthesia in children reported by Cook et $a l^{4}$ In the latter study, the adductor pollicis technique was used with stimuli $(0.25 \mathrm{~Hz}, 0.6 \mathrm{~ms}$ duration) delivered via needle electrodes while $1 \mathrm{mg} \mathrm{kg}^{-1}$ succinylcholine was given intravenously. A stightly longer duration of twitch ablation in the current study is consistent with differences in timing and dose of succinylcholine used by Cook et al. No significant difference in mean duration of twitch depression following succinylcholine was demonstrated among the three anaesthetic groups in the current study. This lack of effect of the volatile agents on the duration of succinylcholine-induced twitch suppression is in agreement with the findings of Lebowitz et al., who demonstrated no difference in duration of twitch suppression following succinylcholine during either enflurane, diethyl ether-nitrous oxide and Innovar-nitrous oxide anaesthesia. ${ }^{\mathrm{s}}$

The overall mean time $(89 \pm 25 \mathrm{~s})$ to loss of twitch after vecuronium administration is comparable to the $96 \pm 6 \mathrm{~s}$ obtained by Goudsouzian et al. In the latter study, loss of twitch (defined as 100 per cent block, utilizing train-offour (TOF) stimulation, stimuli of $0.2 \mathrm{~ms}$ duration via surface electrodes with the adductor pollicis technique) was obtained with vecuronium, $0.08 \mathrm{mg} \cdot \mathrm{kg}^{-1} \mathrm{IV}$, in children ( $2-9$ yr) during halothane ( 1.5 per cent) anaes- 
thesia. ${ }^{6}$ The loss of visible twitch, observed at 95-98 per cent block as determined by the adductor pollicis technique, is obtained earlier than the 100 per cent block used as endpoint in Goudsouzian's study.' However, during halothane ( 0.82 per cent) anaesthesia, 100 per cent block was obtained in $144 \pm 84 \mathrm{~s}$ after a $0.07 \mathrm{mg} \cdot \mathrm{kg}^{-1} \mathrm{IV}$ bolus (stimuli of $0.15 \mathrm{~ms}$ at $0.15 \mathrm{~Hz}$, necdle elcetrodes) ${ }^{7}$ or in $173 \pm 27 \mathrm{~s}$ after a $0.1 \mathrm{mg} \cdot \mathrm{kg}^{-1}$ IV bolus during 0.5 per cent halothane araesthesia (TOF stimuli). ${ }^{8}$ The more rapid onset of twitch ablation in the present study is consistent with the use of a greater depth of inhalational anaesthesia as well as a higher frequency of stimulation. Greater depth of inhalational anaesthesia is associated with a more rapid loss of twitch after vecuronium administration. ${ }^{9}$ A higher rate of stimulation may contribute to a faster onset of twitch ablation and to an apparently faster onset of muscle relaxation. A higher stimulus frequency may enhance blood flow to the thumb, resulting in a faster onset of twitch ablation. ${ }^{10}$ Rates of stimulation higher than $0.1-0.15 \mathrm{~Hz}$ may cause early failure of transmission and apparent relaxation, presumably because of run down of prejunctional acetylcholine release. ${ }^{11.12}$ Interestingly, during ketamine anaesthesia, the loss of twitch ( 100 per cent block), as determined by the adductor pollicis technique (surface electrodes, TOF), was achieved in children in 135 seconds following vecuronium administration, $0.1 \mathrm{mg} \cdot \mathrm{kg}^{-1}$ IV. ${ }^{13}$

The time to loss of twitch after succinylcholine, $1.5 \mathrm{mg} \cdot \mathrm{kg}^{-1} \mathrm{IV}$, in this study, was approximately equal to half the time needed for twitch ablation following vecumonium, $0.1 \mathrm{mg} \cdot \mathrm{kg}^{-1} \mathrm{IV}$, regardless of the anaesthetic agent. This time ratio is the same as the succinylcholine (1.5 mg $\mathrm{kg}^{-1}$ IV)-pancuronium ( $0.15 \mathrm{mg} \cdot \mathrm{kg}^{-1}$ IV) ratio (1:2) recorded in children during a barbiturate-narcotic anaesthesia. ${ }^{2}$ A similar ratio of onset time was documented for succinylcholine and the non-depolarizing blocking agents fazadinium, pancuronium and d-tubocurarine during a barbiturate-narcotic anaesthesia in adults. ${ }^{3}$ Thus, under the conditions of this study, the inhalation agents do not appear to affect the ratio of onset time of clinically used doses of muscle relaxants. It should be noted that the clinically used doses of muscle relaxants in this as well as in the two quoted studies are not equipotent but are, in fact, different multiples of their respective $\mathrm{ED}_{95} \mathrm{~s}$ and, thus, are not strictly comparable from a pharmacokinetic or pharmacodynamic point of view.

Of the three inhalational anaesthetics, halothane, enfluranc and isoflurane, isoflurane increases (doubles) muscle blood flow the most while maintaining cardiac output. ${ }^{14-16}$ This may result in the delivery of a proportionally greater quantity of a neuromuscular blocking agent to the muscle than during halothane or enflurane anaesthesia. ${ }^{17,18}$ Isoflurane may also facilitate a more rapid delivery of succinylcholine to the myoneural junction than other inhalational anaesthetics. ${ }^{19}$ However, the effects of the three inhalation agents on the onset times of either succinylcholine or vecuronium, and on the duration of succinylcholine's action, has not been compared in a comprehensive study under controlled conditions. Under the conditions of this study, no significant difference in the time to (witch ablation was apparent among the three anaesthetic groups for either succinylcholine or vecuronium. Although small differences in onset times among anaesthetic agents may be demonstrable with precision instrumentation under controlled conditions, we suggest that, from a clinical point of view, these differences may be too small to be meaningful in clinical practice.

The depth of (inhalation) anaesthesia was not controlled. Anaesthetic depth is difficult to quantify from clinical signs, ${ }^{20}$ stable inspired anaesthetic levels were not presumed to have been reached and the anaesthetic depth probably varied among patients. However, this variation was probably distributed randomly among patients and groups, mimicking the variable anaesthetic background conditions encountered in clinical practice. Relatively deep levels of anaesthesia were administered to amplify potential haemodynamic differences induced by the anaesthetic agents and thus accentuate their potential neuromuscular effects on onset time. In clinical practice, anaesthesia is usually maintained at a lighter level where haemodynamic changes are less likely to be pronounced.

In conclusion, the visual thumb twitch evoked by transcutaneous stimulation of the ulnar nerve at $1 \mathrm{~Hz}$ is an easily observed end-point, obtainable with simple, inexpensive equipment. It appears adequate for the determination of the onset time and duration of succinylcholineinduced relaxation in pediatric practice, despite differences in stimulating frequency, monitoring technique and anaesthetic background of this and other more controlled studies. ${ }^{21}$ In evaluating vecuronium's onset time, it should be realized that the onset of relaxation may be underestimated with the magnitude of the difference depending on the factors addressed above. Although small differences in onset times may well go undetected in this type of study, the time to twitch ablation after either succinylcholine of vecuronium (at the doses used in this study) or the duration of action of succinylcholinc, does not appear to be substantially affected by the choice of inhalation agent.

\section{Acknowledgement}

We wish to thank Dr. Richard Levin, Department of Anesthesiology, University of Michigan, for his advice 
and editorial comments during the preparation of this manuscript.

\section{References}

I Ali HH, Savarese JJ. Monitoring of neuromuscular function. Anesthesiology 1976; 45: 216-49.

2 Cunliffe M, Lucero VM, McLeod ME, Burrows FA, Lerman $J$. Neuromuscular blockade for rapid tracheal intubation in children: comparison of succinylcholine and pancuronium. Can Anaesth Soc J 1986; 33: 760-3.

3 Blackburn CL. Morgan M. Comparison of speed of onset of fazadinium, pancuronium, tubocurarine and suxamethonium. Br J Anaesth 1978; 50: 361-4.

4 Cook $D R$, Fischer $C G$. Neuromuscular blocking effects of succinylcholine in infants and children. Anesthesiology $1975 ; 42$ : 662-5.

5 Lebowitz MH, Blitt CD, Walls LF, Depression of twitch response to stimulation of the ulnar nerve during Ethrane anesthesia in man. Anesthesiology 1970; 33: 52-7.

6 Goudsouzion NG, Martyn JJA, Liu LMP, Gionfriddo $M$. Safety and efficacy of vecuronium in adolescents and children. Anesth Analg 1983; 62: 1083-8.

7 Fisher DM. Miller RD. Neuromusculas effects of vecuronium (ORG NC45) in infants and children during $\mathrm{N}_{2} \mathrm{O}$, halothane anesthesia. Anesthesiology 1983; 58: 519-23.

8 Ferres $C J$, Crean PM. Mirakhur RK. An evaluation of ORG NC45 (vecuronium) in paediatric anaesthesia. Anaesthesia 1983; 38: 943-7.

9 Hausdoerfer J, Hagemann H, Bell M, Mertinat M. Isofluran in der kinder anaesthesie. Anaesthesist 1986; 35: 345-52.

10 Curran MI, Donati F, Bevan DR. Onset and recovery of atracurium and suxamethonium-induced neuromuscular blockade with simultaneous train-of-four and single twitch stimulation. Br J Anaesth 1987; 59: 989-94.

11 Ali $H H$, Savarese $J J$. Stimulus frequency and the dose response curve to dtc in man. Anesthesiology 1980; 52: $36-9$.

12 Lee C, Katz RL. Neuromuscular pharmacology. A clinical update and commentary. Br J Anaesth 1980; 52: 173-88.

13 Friesdorf $W$, Schultz M, Foenel Th, Altemeyer KH. Pharmakodynamik von vecuronium im kleinkindesalter bei intravenoeser narkose einleitung mit ketamin. Anaesthesist 1986; 35: 99-102.

14 Stevens WC, Cromwell TH, Halsey MJ, Eger EI, Shakespeare $T F$, Bahtman $S H$. The cardiovascular effects of a new inhalational anesthetic, Forane, in human volunteers at a constant arterial carbon dioxide tension. Anesthesiology 1971; 35: 8-16.
15 Eger EI. Smith NT, Stoeling RK, Cullen DJ. Kadis LB, Whitcher $C E$. Cardiovascular effects of halothane in man. Anesthesiology 1970; 33: 396-409.

16 Calverley RK, Smith NT, Prys-Roberts C, Eger EI, Jones $C W$. Cardiovascular effects of enflurane during controlled ventilation in man. Anesth Analg 1978; 57 : 619-28.

17 Miller RD, Way WL, Dolan WM, Stevens WC, Eger EI. Comparative neuromuscular effects of pancuronium, gallamine, and succinylcholine during Forane and halothane anesthesia in man. Anesthesiology 1971; 35: $509-14$.

18 Vitez TS, Miller RD, Eger EI, Van Nyhuis LS, Was WL. Comparison in vitro of isoflurane and halothane potentiation of d-tubocurarine and succinylcholine neuromuscular blockades. Anesthesiology 1974; 41: 53-6.

19 Eger EI. Isoflurane: a review. Anesthesiology 1981; 55: 559-76.

20 Cullen DJ, Eger EI, Stevens WC et al. Clinical signs of anesthesia. Anesthesiology 1972; 36: 21-36.

21 Hudes $E$, Lee $K C$. Clinical use of peripheral nerve stimulators in anaesthesia. Can J Anaesth 1987; 34: 525-34.

\section{Résumé}

Le temps de perte de la réponse du muscle adducteur du pouce suite à une stimulation du nerf cubital à $1 \mathrm{~Hz}$ (twitch) après $1.5 \mathrm{mg}^{-} \mathrm{kg}^{-1}$ (IV) de succinylcholine, ou $0.1 \mathrm{mg} \cdot \mathrm{kg}^{-1}$ intravefneux de vecuronium a été évalué visuellement chez 134 enfants aggés de 2 d 13 ans durant une antesthésie profonde d' l' halorhane, enflurane et isoflurane. Le temps de perte de la réponse musculaire et la durée de l'action de la succinylcholine sont en accord avec les temps déjà publiés lors des conditions expérimentales conrrolées; le début d'action après vécuronium est comparable à celui observé dans les conditions experimentales contrólées, La perte de ta réponse musculaire après succinylcholine a été acquise deur fois plus rapidement qu' avec le vécuronium indépendamment de l'agent anesthésique utilisé. Le début d'action de la succinylcholine et du vecuronium ainsi que la durée d'action de la succinylcholine peuvent âtre adéquatement évalués cliniquement. Le choix de l'agent anesthésique d'inhalation n' affecte pas le temps de la perte de la contraction musculaire d" une façon cliniquement significative et ne présenie aucune différence cliniquement appréciable dans la durée d'acion de la succinylcholine. 